\title{
EL FRANCÈS, UNA LLENGUA AMB CONTINUÏTAT
}

\author{
Isabel Castilleja i Salvador Moreno. Mestres de Llengües estrangeres \\ del CEIP de Pràctiques de Tarragona
}

El Col-legi de Pràctiques ofereix actualment, des de fa quatre cursos, la possibilitat de l'aprenentatge del francès com a segona llengua estrangera. Saber llengües és cada cop més necessari, i molt més ara amb l'expectativa de la Unió Europea, que ja és una realitat. Quina millor llengua a escollir que aquella que es caracteritza per una estructura d'idioma tan semblant a la nostra...Tant és així que, a l'hora d'un plantejament seriós, s'ofereix el francès a tots els alumnes del Cicle Superior amb la intenció de donar una oportunitat d'igualtat per a tots, no tan sols influenciats per la proximitat del país que el parla, sinó també per la predisposició del professorat i dels pares per introduir-la.

Això sí, conscients sempre d'una sèrie de limitacions i amb uns objectius concrets, no gaire ambiciosos, però sí esperançadors, com el de desenvolupar en els alumnes una actitud oberta, receptiva i respectuosa davant aquesta llengua, el seu país d'origen, la seva gent i la seva cultura. No oblidem, tanmateix, altres objectius que enriqueixen diferents destreses intel-lectives, com l'observació, la deducció, etc.

Malgrat tot, no podem pretendre que els nostres alumnes acabin els seus estudis primaris amb coneixements suficients com per poder comunicar-se amb un mínim d'autonomia en aquest idioma; però sí tenim la il-lusió d'activar el seu interès per continuar posteriorment a l'ESO, ampliant el seu aprenentatge, i en el cas de no fer-ho, haver adquirit almenys un vocabulari bàsic per mantenir una mínima comunicació oral.

Aquest projecte va tenir una part de suport i assessorament a càrrec del Centre de Recursos de Llengües Estrangeres, i alguns dels materials utilitzats van ser adaptats i implementats d'acord amb les condicions específiques dels grups en què s'ha treballat.

\section{Organització metodològica i avaluació}

La introducció del francès s'inicia en el Cicle Superior amb una sessió setmanal de 45 minuts. Algunes de les sessions es realitzen segons les activitats programades a l'aula d'idiomes.

Es dóna un enfocament eminentment oral, comunicatiu i lúdic amb la finalitat de desenvolupar la comprensió oral i el gust per la llengua francesa, sense forçar en cap moment l'expressió oral, tot permetent que els alumnes comencin a produir a mesura que se sentin preparats per fer-ho.

S'intenta donar un input oral ric, de forma continuada i amb una bona pronunciació, utilitzant materials diversos $\mathrm{i}$ atractius per mantenir un bon nivell de motivació. Progressivament i al llarg de tot el cicle, es compagina la producció oral amb l'escrita, respectant la demanda dels mateixos alumnes.

La combinació d'activitats amb què es treballa, per parelles, en petit grup o en gran grup, afavoreix també la socialització i la integració de tots els alumnes.

En les primeres classes, ens proposem donar a conèixer característiques pròpies de França, com són: situació geogràfica dins d'Europa, moneda, música, ciutats, monuments $\mathrm{i}$ indrets tan representatius per al món infantil com Eurodisney, el parc d'Axterix i Obelix... En definitiva, imatges que representen aquest país davant el món. Quan ja s'ha aconseguit despertar l'interès de conèixer més aquest país i la seva llengua, presentem a partir de vídeos (una col-lecció de 8 cintes corresponents a vuit unitats de programació repartides en tot el cicle) un personatge peculiar, Pierre, que ens convida a entrar a casa seva, en la seva família i els seus afers quotidians, tan semblants als nostres, ja que es tracta d'un nen amb una edat aproximada a la dels nostres alumnes i que ens apropa amb la seva imaginació al seu món, Le petit mon de Pierre, on un rei fictici ens ajuda a fer-nos entendre les vivències infantils. Així, ens passeja per casa seva, donant-nos l'oportunitat d'aprendre vocabulari i expressions de molts temes actuals que podem ampliar amb altres recursos tecnològics que introduïm en el seu aprenentatge, recursos que ens ajuden en el propòsit de donar a conèixer aquesta llengua d'una forma més atractiva. Així doncs, l'aprenentatge d'aquesta llengua s'efectua des del primer moment per mitjà del seu ús com a eina per practicar a través d'unes activitats, on els veritables protagonistes són els mateixos alumnes.

És inevitable l'avaluació d'aquesta llengua, però per la peculiaritat que l'envolta també el seu seguiment ha de ser diferent. S'han prioritzat els aspectes orals i de participació en les activitats. Quan els alumnes treballen en els diferents racons es procura que ells mateixos autoavaluïn l'activitat que realitzen d'una manera qualitativa més que quantitativa, ja que també serveix per a controlar la feina, mitjançant uns fulls de seguiment 


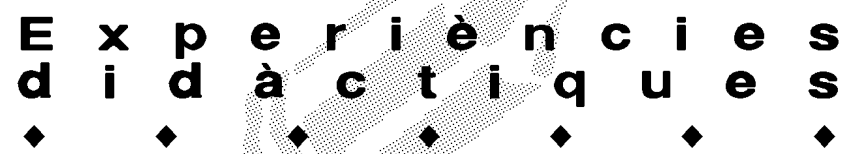

coi.locats en llocs concrets, on van apuntant els seus resultats. Per tant, no serà tan important el nombre de treballs que puguin realitzar, sinó el fet d'haver assolit tot allò que s'hagin proposat fer. Per altra banda, el professor tindrà el seu full de seguiment de tota la classe, on podrà anotar les següents observacions del procés d'aprenentatge dels alumnes:

- Motivació de l'alumne.

- Respecte a les produccins dels altres.

- Participació oral i espontània a classe.

- Participació en activitats que suposen un tipus d'esforç diferent: dramatització, memorització d'embarbussaments...

- Comprensió de missatges senzills.

- Assoliment d'un vocabulari bàsic a nivell oral: salutacions, frases fetes, cançons...

Aquest tipus d'avaluació permet una major implicació dels alumnes en totes les activitats, ja que són conscients que es valora globalment el seu aprenentatge, així com el seu esforç i predisposició.

\section{L'aula d'idiomes i els racons}

El fet de canviar d'espai, de mestre/a o d'ambient motiva també els alumnes a fer un canvi d'actitud, a desconnectar de l'anterior i connectar amb una nova situació. En aquest nou ambient també s'han de regir per unes altres pautes que han de respectar, així com per un altre codi lingüístic.

L'organització de l'aula es flexible, de manera que ens facilita treballar en gran grup o en grups més petits, ja que diferents tipus d'activitats requereixen uns distribució diferent; això ens porta a crear diferents racons de treball per tal de facilitar i atendre millor la diversitat.

El Laboratori Portàtil

Les conegudes «maletes» donen l'oportunitat als alumnes de treballar amb la suficient independència com per poder escollir els temes, i fins i tot les fitxes que han de fer, amb l'avantatge de poder escoltar la gravació tantes vegades com calgui, fer les seves pròpies produccions i autocorregir els seus enregistraments les vegades que ells creguin necessàries.

A grans trets, definiríem aquest petit laboratori com una gran cassette sofisticada, on poden treballar sis alumnes amb auriculars i micròfon per escoltar-repetirenregistrar-autocorregir, que té la possibilitat d'escollir el grau de dificultat segons les necessitats individuals atenent la diversitat de cadascun. Tanmateix, és un sistema d'aprenentatge que ja es pot introduir a l'aula des de l'inici del $2 \mathrm{n}$ trimestre, amb la intenció concreta que els alumnes comencin a produir sense inhibir-se i espontàniament.

Cada nen té la seva cinta de cassette, per a utilitzarla tantes vegades com calgui, afegint o esborrant per intentar millorar la seva pronunciació.

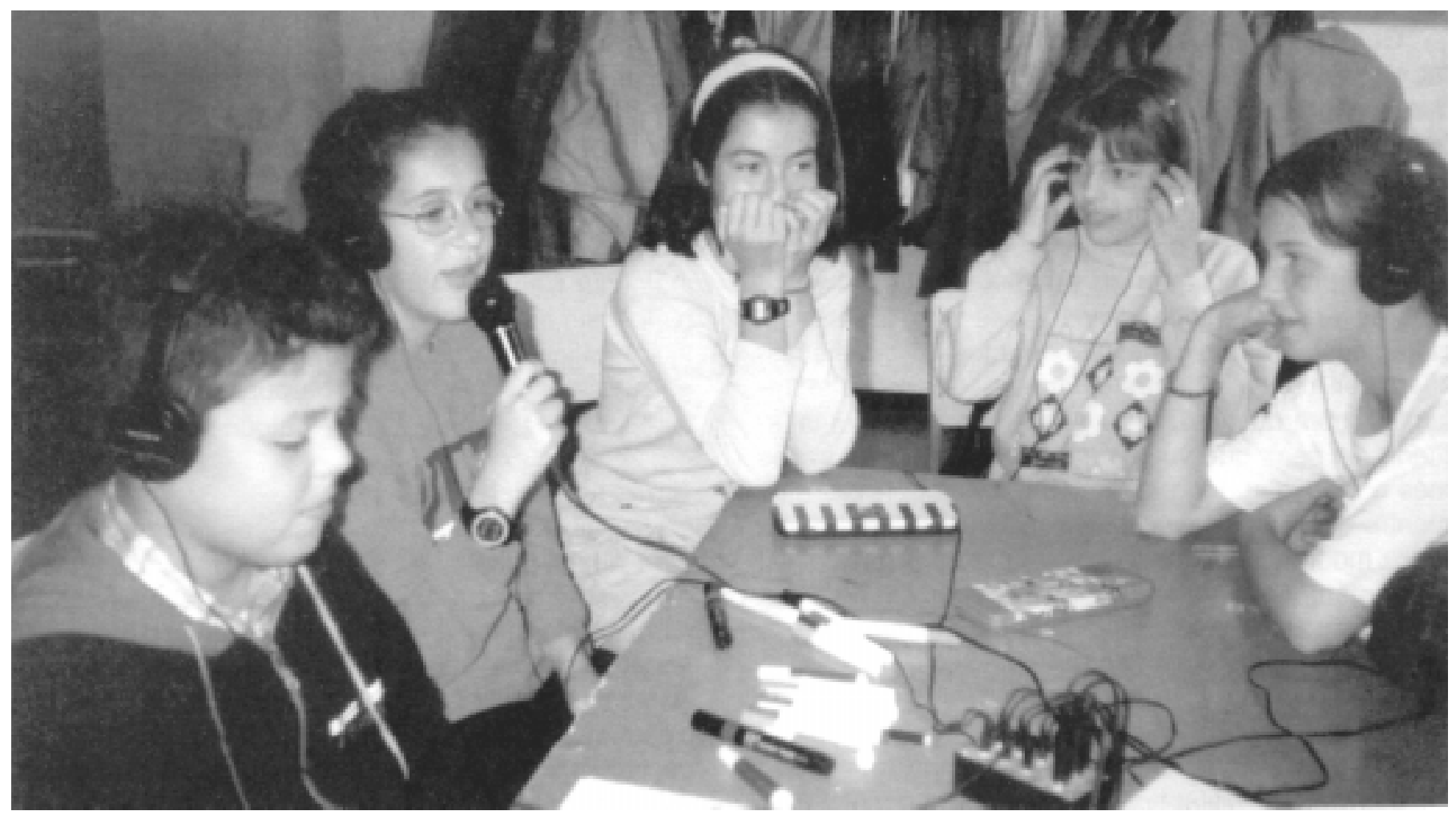




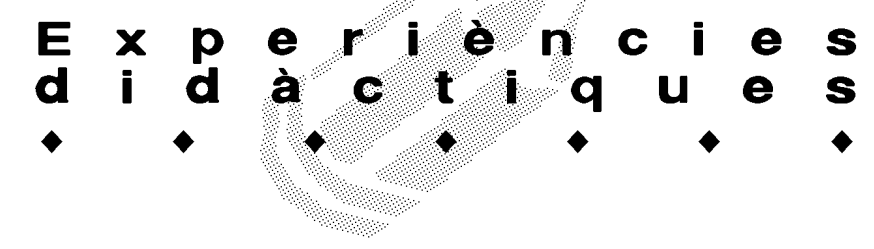

Frases/Missatges

A mesura que el curs va avançant, fins i tot els alumnes més insegurs són capaços de comprendre missatges i situacions senzilles i anar ampliant el grau de dificultat.

Ara és el moment de formular petites frases amb estructures simples, canviant únicament adjectius o noms per anar ampliant el vocabulari conegut:

\section{LA MAISON DE PIERRE EST ROUGE}

LA MAISON DE PIERRE EST JAUNE

LA MAISON DE PIERRE EST ROUGE ET JAUNE.

$O$ bé substituir el nom, o el nom i l'adjectiu:

LA CHAMBREDE PIERRE EST BLEU

Lògicament es juga amb les imatges, i quan la pronunciació de les paraules referents a objectes, salutacions, temps... està assolida, es presenta la seva grafia através de jocs de relació so-dibuix-grafia i viceversa. Per exemple, fer parar taula, amb els seus elements situats correctament: «à gauche», «entre», «à droite»...l per què no dur a terme una recepta del pastís de xocolata que tant li agrada a Pierre? Barrejant els seus ingredients, surten mil possibilitats de treball amb temes tan simples $i$ llaminers.

\section{DRAMATITZACIONS}

Cap al cinquè trimestre es poden plantejar coses més complicades, amb activitats com la dramatització per tal que els més atrevits demostrin les seves capacitats dramàtiques.

Qualsevol tema és factible: imitar oficis, representar els fets quotidians de tot el dia, etc., però un tema que els agrada molt és el dels animals: els intentarem conèixer pel seu nom i després treballarem un conte: $L e$ rat de ville, le rat des champs. Aquesta activitat suposa una preparació prèvia en diferents sessions:

El primer pas és dominar el vocabulari que utilitzarem; després, ambientar els animals en el seu hàbitat natural; fer una sèrie de comparances entre el camp i la ciutat; confegir amb cartolina negra tot allò que necessitem per muntar el teatre d'ombres; i finalment, representar l'obra davant de tots els companys. Voluntàriament, els nens que vulguin, memoritzaran unes frases més o menys curtes i les aniran produint en veu alta, mentre que altres, darrere la pantalla del teatre d'ombres, mouran els personatges tal com s'ha assajat prèviament. El material utilitzat és tan simple com una petita pantalla translúcida, un llum de peu i les figures confegides en cartolina negra.

\section{LA MúsICA}

Un altre aspecte important i que no podem oblidar és la música: sempre ens diu molt d'un país, forma part de la seva sensibilitat i de la seva cultura popular més arrelada. Oferir als nens l'oportunitat de conèixer-la també és apropar-los a l'actualitat dels joves com ells. Les activitats que possibiliten les cançons són variades, des del reconeixement de paraules conegudes fins a la memorització de la part repetitiva de les estrofes, repetint com una cantarella o simplement escoltant pel plaer de fer-ho en qualsevol ocasió que ens pugui acompanyar com a música de fons.

\section{CONTES I REVISTES}

És agradable també poder fullejar revistes juvenils i publicacions tan conegudes com «Axterix i Obelix», que representen un atractiu especial en la seva llengua original.

Els contes ajuden a desenvolupar la imaginació i la fantasia i també activen la motivació envers la llengua contextualitzada, adequada sempre al seu nivell $\mathrm{i}$ amb un suport visual per facilitar-ne la seva comprensió. En els contes es troben moltes frases fetes que es repeteixen i que faciliten la participació de tots els alumnes, al mateix temps que ajuden a reforçar o consolidar molts aspectes de la llengua treballada.

\section{RELAXACIÓ}

De fet els nens de primària són exigents i fàcils de motivar. Una de les coses que més els agrada és fer exercicis de «relaxació», que consisteixen, com bé diu la paraula, a relaxar totes les parts del cos. Els alumnes es col-loquen com més còmodes millor, i concentrats (cal enfosquir una mica l'aula) van deixant anar la part del cos que es va anomenant, des dels dits dels peus i mans, cames, esquena, cap... Aquesta activitat dóna bon resultat aquells dies que els alumnes, pel motiu que sigui, estan més excitats o menys concentrats; a més, serveix com a revisió d'un vocabulari treballat amb anterioritat.

Jocs

Els jocs com el bingo, el dòmino, etc. són bons materials i serveixen molt bé per establir la correspondència entre la llengua oral treballada i la representació gràfica, ja sigui en forma d'imatge o de paraula escrita. Jocs de paraules, embarbussaments, etc... són altres maneres també d'animar algún racó de l'aula.

\section{Altres consideracions}

Tot això i moltes altres coses es poden plantejar, però ja hem parlat anteriorment d'un gran inconvenient -el nombre de sessions-. Una sessió setmanal és poc temps. Malgrat tot, ens queda l'esperança d'haver despertat la innata curiositat dels nostres alumnes per una llengua que en el fons no és difícil, per la similitud d'estructures amb la nostra, i d'haver donat una sèrie de recursos i estratègies que els seran útils com a estudiants i persones. 